\title{
The Pattern of Injury and Workload Associated with Managing Patients After Suicide Attempt by Jumping from a Height
}

\author{
B. Rocos*, M. Acharya and T.J.S. Chesser
}

Department of Orthopaedics, Southmead Hospital, North Bristol NHS Trust, Bristol, BS10 5NB, UK

\begin{abstract}
Purpose: The aim of this study is to examine the pattern of injuries sustained and the hospital workload generated by patients who deliberately jump from height.

Method: One regional trauma centre's admissions were scrutinized to find all patients who jumped, or were suspected of jumping from one storey or greater over a four year period. Patients who died prior to admission were excluded.

Results: 41 patients were included. Each patient suffered a mean of 3 injuries. The probability of calcaneal fracture was 0.32 , of ankle injury 0.2 , tibial fracture 0.2 , femoral fracture 0.17 , pelvic fracture 0.34 , spinal injury 0.51 , upper limb injury 0.26 , head injury 0.2 and trunk injury 0.32 . The mean length of inpatient stay was 7.9 days, rising to 17.9 for the 11 patients requiring intensive care. The average number of operations per patient was 1.5 .

Conclusion: Patients who jump from height generate large volumes of operative and inpatient workloads. Our data show that there may be a protective effect of limb trauma against lethal head, chest or pelvic injury. Injury to the upper limb is associated with a 4 times greater risk of head injury. The incidence of pelvic injury in this series is higher than in previous work. There was a high incidence of spinal fracture. Patients generated 64 surgical procedures and consumed a mean of 17.9 inpatient days, including prolonged stay in intensive care.
\end{abstract}

Keywords: Height, jump, multidisciplinary, polytrauma, suicide, trauma.

\section{INTRODUCTION}

Jumping from a height accounts for between $3-15 \%$ of the 140,000 suicide attempts in the UK each year [1-3]. Jumping requires little in the way of planning and skill to carry out and causes multiple severe injuries in those who survive [4].

According to the literature, those who attempt suicide by jumping from a height display common characteristics. They are predominantly male, middle aged, unemployed and single. $19-97 \%$ of patients have a psychiatric diagnosis (most commonly schizophrenia) which is more severe than that suffered by those who employ other methods of suicide $[2,5-11]$. The injuries sustained and the injury severity score is correlated to the height of the jump, the surface on which they land and position of the patient on landing [4, 6, 12-14].

The aim of this analysis of a retrospective case series is to examine the pattern of injuries sustained and the hospital workload generated by the management of patients who deliberately jump from height.

\section{METHODS}

The orthopaedic admission database (Bluespier, Bluespier International Ltd, Droitwich UK) of one regional centre was interrogated using keywords and injury descriptions from clinic letters and ward rounds combined

*Address correspondence to this author at the Department of Orthopaedics, Southmead Hospital, North Bristol NHS Trust, Bristol, BS10 5NB, UK; Tel: 0117 9505050; E-mail: brett.rocos@bristol.ac.uk with Boolean operators to find all patients who had either jumped or were suspected of jumping from any height between August 2008 and August 2012. No age limits were placed on the search (the unit was the regional adult and paediatric neurosurgical, orthopaedic and plastic surgical trauma centre). Where doubt existed as to whether the mechanism was a jump or fall of the patient was included as falls were more likely to have been in the presence of witnesses or be elucidated from the presentation or circumstance of the injury. Records were examined to identify those patients whose height of jump was one storey (equating to 10 feet, 3 metres) or greater. Case notes were utilised to collect the data shown in Table 1. Patients who died prior to admission were excluded. Records held at other acute and mental health trusts were not accessed. Blood toxicology reports were not sought in any cases as these are not routinely performed unless criminality is suspected.

\section{RESULTS}

Over the four year period 41 patients met the inclusion criteria for the study, of which 14 were female. The ages of patients was normally distributed about a mean of 32 years (Fig. 1). A previous psychiatric diagnosis had been established in 23 of the 41 patients, of which depression $(10 / 41)$ was the commonest, followed by psychosis $(6 / 41)$. Eighteen of the 41 patients had no documented diagnosis or evidence of a mental health condition prior to their jump. All patients landed on firm surfaces, 1 onto unpaved ground, the remainder onto road or paved surfaces. 


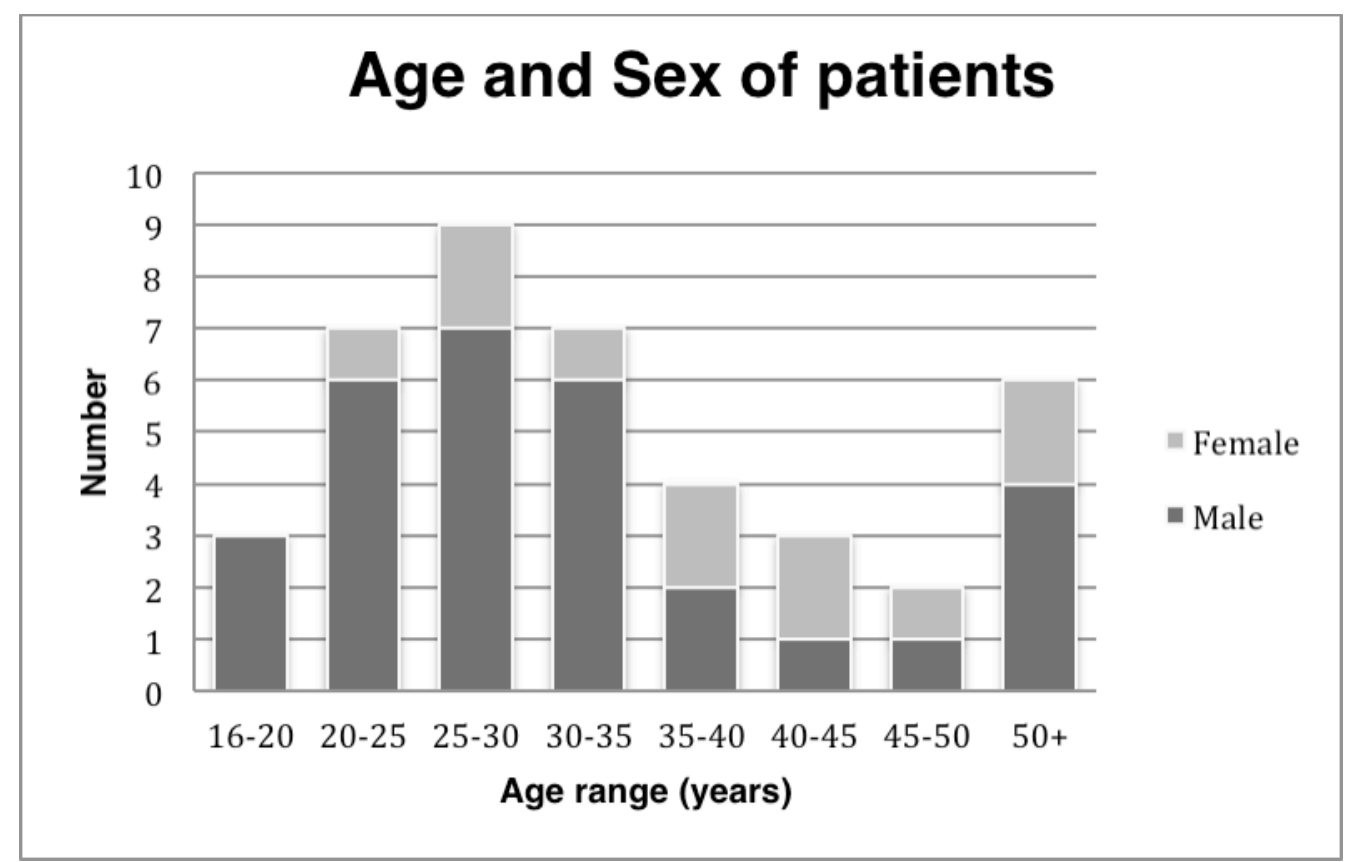

Fig. (1). The age and sex of patients included in the retrospective case series of patients who jumped from a height greater than 3 metres between 2008 and 2012.

Table 1. Data recorded from case notes and electronic records of each of 41 patients included in the retrospective case series

\begin{tabular}{|c|c|}
\hline Height of Jump & Treatment \\
\hline Injuries sustained & Specialities involved \\
\hline Number of theatre visits & Psychiatric diagnosis \\
\hline Length of stay & Injury severity score (ISS) \\
\hline Landing surface & \\
\hline \\
Data were interpreted using Microsoft Excel 2010 (Microsoft, Redmond, WA). \\
Statistical tests were carried out using SPSS v.20 (SPSS Inc, Chicago, IL).
\end{tabular}

When taken as a group, patients suffered a mean of three distinct injuries ranging from head injury to minor foot trauma. The incidence of specific injuries is shown in Table 2 .

The median injury severity score (ISS) at presentation was 15 (range 4-50); 13 patients had an ISS less than 9, 8 patients an ISS of 9- 15 and 20 patients an ISS of 16 or greater. These scores showed no correlation of age. The mean height of jump was 30 feet (10 metres) with injury severity showing a positive correlation with respect to the height of jump $(r=0.651)$. The analysis did not take into account of those patients who died prior to arrival in the emergency department, however one patient died during admission.

Injury of feet was reported in $25 \%$ (excluding the os calcis). When taken as a separate entity, calcaneal injuries occurred in $13 / 41$ patients $(32 \%)$, which were open fractures in one quarter of cases [15]. No patient suffered an open ankle injury. Patients showed a 1 in 5 chance of sustaining a closed ankle injury. There was a $20 \%$ chance of patients sustaining a tibial fracture, of which $50 \%$ were open.
Femoral fractures occurred in 7/41 patients; a single case was open.

Table 2. The Frequency of injuries sustained to defined anatomical areas after a jump from height of greater than 3 metres seen in a retrospective case series of 41 patients.

\begin{tabular}{|c|c|c|c|}
\hline Injury & Closed & Open & Total \\
\hline \hline Foot & 8 & 1 & 9 \\
\hline Calcaneum & 10 & 3 & 13 \\
\hline Ankle & 9 & 0 & 9 \\
\hline Tibia & 3 & 4 & 7 \\
\hline Femur & 6 & 1 & 7 \\
\hline Pelvis & 13 & 1 & 14 \\
\hline Lumbar spine & 14 & - & 14 \\
\hline Abdomen & 3 & - & 3 \\
\hline Chest & 10 & - & 10 \\
\hline Thoracic spine & 8 & - & 8 \\
\hline Upper limb & 8 & 3 & 5 \\
\hline Cervical spine & 5 & - & 4 \\
\hline Head & 8 & 0 & \\
\hline Facial injury & 4 & 0 & \\
\hline
\end{tabular}

Pelvic and acetabular fractures occurred in 14/41 patients (34\%). H shaped sacral fractures were diagnosed in $4 / 14$ cases [16]. One of these patients (1/4) showed a mixed $\mathrm{H}$ shaped and vertical shear (VS) pattern. Two patients sustained an acetabular injury in addition to the $H$ shaped sacral fracture. Of the remaining 10 pelvic injuries, one 
sustained an open iliac wing fracture with an associated acetabular injury; two acetabular fractures only; five a lateral compression (LC) fracture; one anteroposterior compression (APC) fracture and one a vertical shear pattern. Overall, 1 in 5 patients with a pelvic ring injury sustained an acetabular fracture.

Upper limb injuries occurred in 11/41 cases. One third of these were open. No extremity fractures were associated with neurovascular compromise. Patients suffered abdominal injuries in 3/41 cases. A single patient required a laparotomy. Ten patients sustained chest injuries. The only treatment required in any patient was a chest drain.

Just over half of patients sustained spinal injuries (21/40). One third of these were lumbar spine injuries, four were confined to the thoracic spine and a single patient sustained an isolated cervical spine injury. Eight patients had multilevel spinal injuries; four sustained cervicothoracic and four thoracolumbar fractures. Eight patients required urgent surgery to manage their spinal injuries. Three patients were left with neurological deficits.

Neurosurgical intervention for severe head injury was required in four cases. Three patients suffered a major head injury not requiring urgent surgery. All patients with severe head injuries required treatment in intensive care (ITU). Five patients sustained minor head or facial injuries. The mean length of inpatient stay was 7.9 days (0-97). 11 patients required treatment in intensive care for between 1 and 55 days (mean of 3.6 days). For those patients who required a stay in ITU, overall mean length of stay increased to 17.9 days (median 10 days). On average, patients required at least one surgical procedure. Orthopaedic surgery was required in 32 cases, neurosurgery in eight, plastic surgery in six, maxillofacial surgery in two, general surgery and ophthlalmology in one case each.

The calculated probability of sustaining an injury to a given region is shown in Table 3.

Table 3. The probability of sustaining an injury to defined structures after a jump from height from greater than 3 meters.

\begin{tabular}{|c|c|}
\hline Injury & Probability \\
\hline \hline Calcaneal fracture & 0.32 \\
\hline Ankle fracture & 0.2 \\
\hline Tibial fracture & 0.2 \\
\hline Femoral fracture & 0.17 \\
\hline Pelvic fracture & 0.34 \\
\hline Spinal injury & 0.51 \\
\hline Upper limb fracture & 0.26 \\
\hline Chest/ abdo injury & 0.32 \\
\hline Head injury & 0.2 \\
\hline
\end{tabular}

\section{DISCUSSION}

This work describes the injuries sustained by patients who jump from height and the resources necessary to treat them. In doing so, it helps the treating team to look for common injury patterns.

The characteristics of our study population are broadly similar to those described in the literature, the principle difference being that $44 \%$ of this cohort show no established psychiatric diagnosis prior to jumping [2, 5-7, 17]. In the UK, mental health trusts keep separate records to acute trusts, and these were not available during the study. Despite this, our study shows similar rates of injury to previously published work. $54 \%$ of our patients suffered spinal injuries, which concurs with figures of $38-80 \%$ in the literature [2, 4$6,18,19] .24 \%$ sustained chest injuries, $34 \%$ pelvic injuries and $20 \%$ head injuries, all within ranges previously published [2, 4-6, 19-21]. Data from this study show an incidence of limb fracture of $93 \%$ in contrast to published figures of 38 to $60 \%[2,4,6,18,19,21]$. However, the majority of previous work includes patients who died in their analyses; there may be an effect of limb trauma being protective against lethal head, chest or pelvic injury.

Our series, though small, shows that the probability of sustaining head, upper limb, chest and abdominal injury when lower limb and pelvic trauma has been sustained is 0.48 , suggesting the possibility that injuries to these areas protect the head and torso. For those patients who sustained injuries to both the upper and lower body (where the division is the L5/S1 junction), 38\% were predominantly left sided direct injuries, $23 \%$ were predominantly right-sided direct injuries and $38 \%$ were bilateral impact injuries, perhaps indicating patients where attitude on landing was in a lateral, supine or prone position.

Fractures to the lower limbs protected the pelvis from injury. The probability of pelvic injury when lower limb injuries occur is 0.74 when compared with pelvic injury in the absence of lower limb fractures. In contrast, injury to the upper limb is associated with a 4 times greater risk of injury to the head.

The incidence of pelvic injury in this series is higher than previous estimates (34\% vs 25\%). H shaped sacral fractures occurred in $10 \%$ of patients (16). Fang et al. showed an incidence of $29 \%$ simple pelvic fractures, $13.7 \%$ vertical shear and 28\% lateral compression fractures in a series of 248 pelvic injuries due to falls from height in 2008 [20]. In comparison our series shows an incidence of $36 \%$ of lateral compression fractures, $14 \%$ of vertical shear pattern and $14 \%$ of anteroposterior compression injury.

Few patients in this series sustained severe head and cervical spine injuries. Dickinson et al. found that injuries in the head and chest were significant predictors of mortality $(\mathrm{p}<0.005)$, and patients with these injuries died from a lower height of fall [22]. This is supported by Richter et al. who showed a $50 \%$ mortality of patients sustaining head injury a falling from a single storey [6]. Patients with these injuries have a reasonable probability of dying prior to admission, and so would be excluded from the study.

Managing these patients requires a multidisciplinary approach and consumes significant resource. In this series, orthopaedic opinion was required in every case, neurosurgical and intensive care input in eight each $(20 \%)$. Reviewing the literature shows that orthopaedics is required in $71 \%$ of cases, neurosurgery in $21 \%$ and intensive care in 
$24 \%$ for patients who jump or fall from height [4]. These patients represent a substantial workload for operating theatres, with each patient requiring a mean of 1.5 theatre visits. The 32 patients requiring surgery visited theatre 64 times, though mostly only once. In one case a patient required 8 separate operations prior to discharge.

The average financial cost of managing these patients is difficult to calculate. Each patient requires a different number of operative procedures, with differing amounts of time and equipment resource allocated to each case. In the National Health Service, the mean cost of intensive care is between $£ 1700-2000$ per twenty four hour period, with normal inpatient ward care costing $£ 250$ per day [23]. The mean cost of acute inpatient care, excluding prior or subsequent mental health care and operative procedures is approximately $£ 10,925$. In one case with prolonged intensive care and inpatient stay, this rose to at least $£ 120,500$, again excluding operative procedures (of which there were eight) and the implants and equipment associated with these.

There are limitations to this case series, including its retrospective methodology and the potential absence of patients who sustained isolated head, abdominal and thoracic injuries. Any patient who died prior to admission was excluded and although the number of patients in the cohort is small, it is likely to represent the majority of patients who jumped from height within our region during the time period examined.

\section{CONCLUSION}

Patients sustained multiple injuries following a jump from height that required the input of the majority of surgical specialties. The typical patient is male, middle aged and has pelvic, spinal and limb injuries. Patients generate large volumes of operative and inpatient workloads. It seems that limb injuries protect the trunk and pelvis.

\section{CONFLICT OF INTEREST}

The authors confirm that this article content has no conflict of interest.

\section{ACKNOWLEDGEMENTS}

Declared none.

\section{REFERENCES}

[1] Health Statistics Quarterly 2003 Available from: http://www.ons. gov.uk/ons/rel/hsq/health-statistics-quarterly/no--20--winter-2003/i ndex.html. Accessed $17^{\text {th }}$ June 2015
[2] Gore-Jones V, O'Callaghan J. Suicide attempts by jumping from a height: a consultation liaison experience. Australas Psychiatry 2012; 20(4): 309-12.

[3] Choices N. Suicide - Causes - NHS Choices: Department of Health; 2014 [updated 2014-22-10]. Available from: http://www. nhs.uk/Conditions/suicide/Pages/Causes.aspx. Accessed $17^{\text {th }}$ June 2015

[4] Beale JP, Wyatt JP, Beard D, Busuttil A, Graham CA. A five year study of high falls in Edinburgh. Injury 2000; 31(7): 503-8.

[5] de Moore GM, Robertson AR. Suicide attempts by firearms and by leaping from heights: a comparative study of survivors. Am J Psychiatry 1999; 156(9): 1425-31.

[6] Richter D, Hahn MP, Ostermann PA, Ekkernkamp A, Muhr G. Vertical deceleration injuries: a comparative study of the injury patterns of 101 patients after accidental and intentional high falls. Injury 1996; 27(9): 655-9.

[7] Nielssen O, Glozier N, Babidge N, et al. Suicide attempts by jumping and psychotic illness. Aust N Z J Psychiatry 2010; 44(6): 568-73.

[8] Sims A, O'Brien K. Autokabalesis: an account of mentally ill people who jump from buildings. Med Sci Law 1979; 19(3): 195-8.

[9] Small GW, Rosenbaum JF. Nine psychiatric inpatients who leaped from a height. Can J Psychiatry 1984; 29(2): 129-31.

[10] Kontaxakis V, Markidis M, Vaslamatzis G, Ioannidis H, Stefanis C. Attempted suicide by jumping: clinical and social features. Acta Psychiatr Scand 1988; 77(4): 435-7.

[11] Cantor $\mathrm{CH}$, Hill MA, McLachlan EK. Suicide and related behaviour from river bridges. A clinical perspective. $\mathrm{Br} \mathrm{J}$ Psychiatry $1989 ; 155: 829-35$.

[12] Gill JR. Fatal descent from height in New York City. J Forensic Sci 2001; 46(5): 1132-7.

[13] Simonsen J. Injuries sustained from high-velocity impact with water after jumps from high bridges. A preliminary report of 10 cases. Am J Forensic Med Pathol 1983; 4(2): 139-42.

[14] Li L, Smialek JE. The investigation of fatal falls and jumps from heights in Maryland (1987-1992). Am J Forensic Med Pathol 1994; 15(4): $295-9$

[15] Gustilo RB, Anderson JT. Prevention of infection in the treatment of one thousand and twenty-five open fractures of long bones: retrospective and prospective analyses. J Bone Joint Surg Am 1976; 58(4): 453-8.

[16] Roy-Camille R, Saillant G, Gagna G, Mazel C. Transverse fracture of the upper sacrum. Suicidal jumper's fracture. Spine 1985; 10(9): 838-45.

[17] Copeland AR. Suicide by jumping from buildings. Am J Forensic Med Pathol 1989; 10(4): 295-8.

[18] Teh J, Firth M, Sharma A, Wilson A, Reznek R, Chan O. Jumpers and fallers: a comparison of the distribution of skeletal injury. Clin Radiol 2003; 58(6): 482-6.

[19] Katz K, Gonen N, Goldberg I, Mizrahi J, Radwan M, Yosipovitch Z. Injuries in attempted suicide by jumping from a height. Injury 1988; 19(6): 371-4.

[20] Fang JF, Shih LY, Lin BC, Hsu YP. Pelvic fractures due to falls from a height in people with mental disorders. Injury 2008; 39(8): 881-8.

[21] Liu CC, Wang CY, Shih HC, et al. Prognostic factors for mortality following falls from height. Injury 2009; 40(6): 595-7.

[22] Dickinson A, Roberts M, Kumar A, Weaver A, Lockey DJ. Falls from height: injury and mortality. J R Army Med Corps 2012; 158(2): 123-7.

[23] Sharif S. The Intensive Care Society - Welcome page 2015. Available from: http://www.ics.ac.uk/. Accessed $17^{\text {th }}$ June 2015 